\title{
Rapid Quantitation by PCR of Endomycorrhizal Fungi Colonizing Roots
}

\author{
Luc Simon, Roger C. Lévesque, ${ }^{1}$ and Maurice Lalonde
}

Centre de recherche en biologie forestière, Faculté de foresterie et de géomatique, and ${ }^{1}$ Département de microbiologie, Faculté de médecine, Université Laval, Sainte-Foy, Québec G1K 7P4, Canada

The VANS1/NS21 primer pair is useful for specifically amplifying a 550bp ribosomal (r) DNA fragment from arbuscular endomycorrhizal fungi, directly from colonized root extracts. A procedure to quantitate these obligatory biotrophs rapidly, based on competitive PCR, was developed by constructing a suitable internal standard to be used with these primers. A 130-bp deletion in the Glomus mossae VANS1/NS21 amplified rDNA fragment was produced by amplifying separately external portions of that fragment, followed by ligation and amplification using the original external primers. When this deleted fragment was added to $G$. mossae rDNA, amplification using VANS1/ NS21 primers yielded the two expected products of $430 \mathrm{bp}$ and 550 bp, respectively, resolved by agarose electrophoresis. This fragment was cloned into the pCL1920 plasmid, a low-copy-number vector (five copies per cell), and mixed with the roots to be analyzed. This provides for a rapid quantitative assay because both steps-extraction of DNA from colonized roots and PCR amplificationare taken into account by the same internal standard. Using this procedure, a sample of colonized leek roots (Allium porum $\times$ Glomus vesicuIIferum) was shown to contain $5 \times 10^{4}$ copies of arbuscular endomycorrhizal fungi rDNA genes per milligram of fresh weight. simple way of getting quantitative information such as gene copy number from PCR amplification assays is by competitive $P C R,{ }^{(1-3)}$ where a known amount of internal standard is added to the sample. This internal standard should be a DNA molecule that can be amplified by the same primer pair as the desired target, but yields a product that is easily distinguished from its counterpart. The DNA used as internal standard should be as similar as possible to the target DNA template to minimize bias during PCR assays. The ratio of amplified template versus amplified standard reflects the ratio of initial template versus initial standard, provided both were subjected to exactly the same PCR conditions and the ratios were close to 1 . Hence, the determination of the initial concentration of template becomes a simple assessment of the concentration of a known DNA standard needed for equimolar production of both amplification products.

Since the VANS1/NS21 primer pair was demonstrated to amplify a fragment of approximately $550 \mathrm{bp}$ from the gene coding for the small subunit rRNA (SSU) of all arbuscular endomycorrhizal fungi tested, ${ }^{(4)}$ a quantitative assay based on this system could find numerous applications. Furthermore, for the first time, the procedure developed and proposed takes into account variation in fungal DNA extraction yield from colonized roots.

\section{METHODS}

\section{PCR Conditions}

The reaction mixtures consisted of template solution and a master mix $(20 \mathrm{~mm}$ Tris- $\mathrm{HCl}, \mathrm{pH} 8.4,100 \mathrm{mM} \mathrm{KCl}, 3 \mathrm{~mm}$
$\mathrm{MGCL}_{2}, 0.02 \%$ gelatin, $200 \mathrm{~mm}$ of each nucleotide) (1:1 vol/vol) containing 25 units/ml Taq DNA polymerase (Amplitaq, Perkin-Elmer Cetus, Montréal, Québec) and $500 \mathrm{pmoles} / \mathrm{ml}$ of two appropriate primers in $20-100 \mu$ l total reaction volume, overlaid with light mineral oil. For the production of labeled products, dNTPs concentration was reduced by $50 \%$ and $10 \mathrm{MBq} / \mathrm{ml}\left[\alpha^{35} \mathrm{~S}\right] \mathrm{dATP}$ added. The temperature profile was programmed on a DNA Thermal Cycler (Perkin-Elmer Cetus) to repeat 25-35 times a cycle of denaturation $\left(60 \mathrm{sec}\right.$ at $\left.94^{\circ} \mathrm{C}\right)$, annealing $\left(45 \mathrm{sec}\right.$ at $\left.50^{\circ} \mathrm{C}\right)$ and polymerization $\left(60 \mathrm{sec}\right.$ at $\left.72^{\circ} \mathrm{C}\right)$, followed by a final extension step of $10 \mathrm{~min}$ at $72^{\circ} \mathrm{C}$. The following oligonucleotides were used as primers:

VANS1(4), 5'-GTCTAGTATAATCGTTATACAGG;

NS21(4), 5'-AATATACGCTATTGGAGCTGG;

NSVA340, 5'-GGCCAGATCTAAGTTGATAGGGCAGAAA;

NSVA470, 5'-GCACGGATCCGGGGAGGTAGTGACAATA

\section{Construction of the Internal Standard}

Primers NSVA340 and NSVA470 were synthesized on the Pharmacia Gene Assembler Plus (Pharmacia LKB Biotechnology, Baie d'Urfé, Québec), and purified on Oligo-Pak minicolums (Millipore, Burlington, MA). Using Glomus mossae amplified ribosomal (r) DNA as template, two PCR amplifications were performed with the VANS1/NSVA340 and NSVA470/NS21 primers. After verification by agarose gel electrophoresis that amplified DNA fragments were of $270 \mathrm{bp}$ and $170 \mathrm{bp}$, respectively, they 
were purified by centrifugal ultrafiltration (Millicon, Millipore, Burlington, MA). Compatible restriction sites with cohesive ends to facilitate subsequent ligation were incorporated into primers NSVA340 (BglII) and NSVA470 (BamHI). Approximately $100 \mathrm{ng}$ of each amplified fragment was digested with the appropriate restriction enzyme for $1 \mathrm{hr}$ at $37^{\circ} \mathrm{C}$. An aliquot $(<1 \mathrm{ng})$ of the ligation mixture was then amplified using the VANS1/NS21 primers to yield the truncated product having an expected 430bp size.

\section{Cloning}

The pCL1920 low-copy-number plasmid vector ${ }^{(5)}$ was selected for cloning the amplified truncated rDNA. Approximately 1 $\mu \mathrm{g}$ of plasmid obtained from $100 \mathrm{ml}$ of exponential culture (Qiagen tip-5, Qiagen Inc., Chatsworth, CA) was digested with $S m a I$ in a final volume of $20 \mu l$. The PCR-amplified 430-bp rDNA fragment was blunt-ended by treating $200 \mathrm{ng}$ of product, $2 \mu$ l of $10 \times$ buffer, $1 \mu$ l of 0.5 mM dNTPs, and 5 units of Klenow for 15 min at $30^{\circ} \mathrm{C}$, followed by $10 \mathrm{~min}$ at $75^{\circ} \mathrm{C}$. Ligation of $100 \mathrm{ng}$ of the treated fragment was done with $250 \mathrm{ng}$ of linearized pCL1920 plasmid DNA and 5 units of T4 DNA ligase, overnight at room temperature, in a total volume of $50 \mu \mathrm{l}$. The ligation mixture was then purified by centrifugal ultrafiltration and approximately $50 \mathrm{ng}$ was used for electrotransformation (Gene-Pulser apparatus, BioRad, Mississauga, Ontario) of Escherichia coli XL1-Blue (Stratagene, La Jolla, CA).

\section{Enumeration of Bacteria}

Electroporated cells were plated on Luria-Bertani plates supplemented with tetracycline $(12.5 \mu \mathrm{g} / \mathrm{ml})$, streptomycin $(100 \mu \mathrm{g} / \mathrm{ml}), X$-gal $(1 \mathrm{mg})$, and the IPTG (0.1 mM). A number of white colonies were selected and tested for the presence of the insert by performing PCR using VANS1/NS21 primers directly on crude DNA extracts. ${ }^{(6)}$ A clone was selected and the recombinant plasmid was named pSTVA1, which had the insertion of a single copy of the 430-bp fragment. Cells from 1 liter of exponential growth were harvested, washed, resuspended in $10 \mathrm{ml}$ of $10 \%$ glycerol, aliquoted in $100 \mu \mathrm{l}$, and stored at $-80^{\circ} \mathrm{C}$. Cell concentration was estimated by microscopic enumeration and colony counts to be $6 \times 10^{10} / \mathrm{ml}$.

\section{DNA Extraction and Competitive PCR}

Liquid nitrogen ground leek roots ( $\mathrm{Al}$ lium porum) colonized with Glomus vesiculiferum were placed in a microcentrifuge tube and weighed. A known amount of freshly thawed and diluted bacterial cells containing the pSTVA1 plasmid was added. The sample was resuspended in $100 \mu \mathrm{l}$ of buffer with a miniature pestle and subjected to three freeze-thaw cycles; total DNA was extracted using the IsoQuick extraction kit (MicroProbe Corp., Bothell, WA), and dissolved in $100 \mu$ l of water overnight at $4^{\circ} \mathrm{C}$. Competitive PCR was carried out on $5 \mu \mathrm{l}$ of DNA extract using the VANS1/ NS21 primers. PCR products were analyzed by agarose gel electrophoresis on $2 \%$ Nusieve/1\% agarose, stained with ethidium bromide, and photographed.
Quantitation of the relative intensity of the bands in a given gel lane was achieved by computer densitometry of the digitized gel pictures using Image v1.41 software (W. Rasband, NIH) running on a Macintosh II. A ScanJet Plus scanner (Hewlett-Packard, Mississauga, Ontario) was used for positive prints and a CCD72 video camera (DAGE MTI, Michigan City, IN) was used. QuickCapture frame grabber (Data Translation Inc., Malboro, MA) were used for negatives.

\section{RESULTS}

The construction of a truncated rDNA fragment within the SSU gene was accomplished by ligation of two separately amplified portions of the G. mossae 550bp fragment (Fig. 1). The resulting 430 -
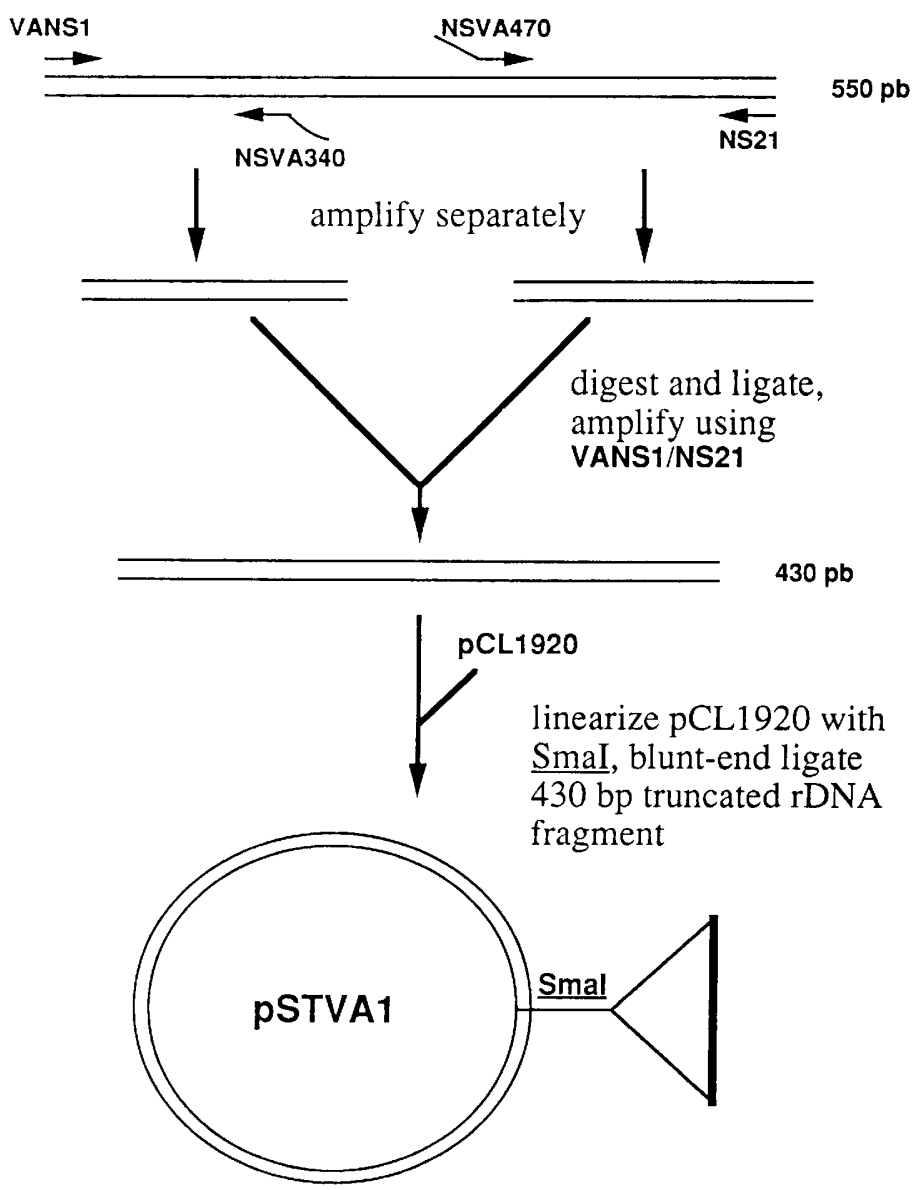

FICURE 1 Diagram of the strategy used to construct and clone a truncated rDNA fragment. Restriction sites were included during the synthesis of the internal primers NSVA340 and NSVA470. The two external fragments were separately amplified, digested with the appropriate restriction enzyme, and ligated. The expected 430-bp fragment was amplified from the ligation mixture using the VANS1/NS21 primers. The pCL1920 plasmid vector was linearized with SmaI and blunt-end ligated to the truncated rDNA fragment to produce the pSTVA1 plasmid. 
bp fragment was identical to the amplified fungal rDNA gene fragment, except for a deletion of $120 \mathrm{bp}$ that allows discrimination in agarose gels following competitive PCR with VANS1/NS21 primers (Fig. 2). Quantitation of the ratio of the two 550-bp and 430-bp products was obtained by photographing the ethidium bromide-stained gel, digitizing the picture, and obtaining a densitometric profile of each gel lane using image analysis software. To verify that the intensity of ethidium bromide staining was linear, $\left[{ }^{35} \mathrm{~S}\right]$ dATP was added to the PCR assay and, following amplification and ethidium bromide staining, the gel was dried and analyzed by autoradiography for $48 \mathrm{hr}$ (Fig. 2). The ratios of 550bp versus 430-bp band intensity obtained from autoradiography and ethidium bromide staining were similar when in the $10-0.1$ range. Because more precise quantitation should rely on ratios close to 1 , densitometric quantitation of stained gels is thus adequate. When the final ratio of amplified standard to template is higher than 10 (or lower than 0.1 ), the relationship between the two types of molecules initially present is no longer linear. This result has also been observed previously. ${ }^{(1)}$ Indeed, when $G$. mossae DNA was mixed in 10-fold increments with the truncated internal standard that we constructed, both amplified products could only be visualized if the initial ratio was between

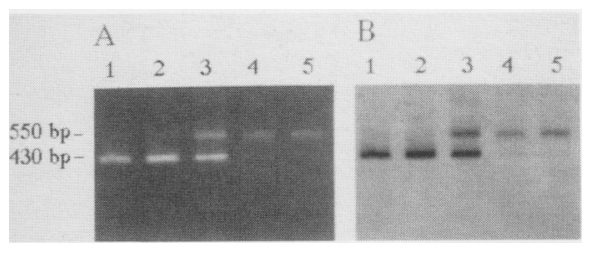

FIGURE 2 Comparison of ethidium bromide staining and autoradiography. Amplified $G$. mossae SSU rDNA was mixed with the amplified 430-bp truncated rDNA fragment in different ratios: 1/20 (lane 1), 1/10 (lane 2), 1/1 (lane 3), 10/1 (lane 4), and 20/1 (lane 5). The ratios represent volumes of the respective species used, not exact amounts in the assay. After 30 cycles of PCR using the VANS1/NS21 primers with $\left[\alpha^{35}\right.$ S]dATP added, 10- $\mu$ l aliquots were analyzed by agarose gel electrophoresis. The gel was stained in ethidium bromide, photographed $(A)$, dried, and autoradiographed $(B)$. The image obtained after a 2-day exposure is similar to the photograph of the ethidium bromide-stained gel, as is the ratio of the two bands visible in lanes 3 .
$10^{2}$ and $10^{-2}$; otherwise the minority DNA was competed out and only the majority product observed.

A direct consequence of having homologous DNA fragment as internal standard is that heteroduplex molecules can be formed. ${ }^{(7)}$ Although heteroduplex formation should not affect the yield of amplification, the presence of such molecules at the end of the PCR is a concern for accurately measuring the concentration ratios of the two products. In some quantitative PCR experiments using VANS1/NS21 primers, we observed an extra band migrating slightly slower than the 550-bp fragment. To demonstrate that this was the manifestation of heteroduplex formation, the 430-bp and 550-bp fragments were amplified separately. A radioactive label was included during the amplification of the 430-bp fragment. Aliquots of the two products were mixed, subjected to various denaturation-renaturation temperature regimes, and analyzed by agarose gel electrophoresis (Fig. 3). The presence of the extra band on the ethidium bromidestained gel is caused by the denaturation of two PCR products and their rapid renaturation. The extra band consists of heteroduplex molecules, as is further confirmed by the detection of radiolabel originating from the 430-bp fragment. Detection of radiolabel in the band corresponding to the 550-bp fragment was due to residual Taq polymerase activity and the availability of $\left[{ }^{35} \mathrm{~S}\right] \mathrm{dATP}$. To quantitate the ratio of the two products accurately, the formation of heteroduplex molecules should be minimized. This can be done during PCR experiments by subjecting the denatured mixture to a very slow decrease in temperature, especially near their melting point, so as to favor the reannealing of homoduplexes (Fig. 3 and Fig. 5, below). The slow renaturing step can easily be programmed as the last step of the PCR.

The possibility that the size difference between the two fragments introduces a bias during the PCR amplification was investigated. The 550-bp and 430-bp fragments were amplified separately and purified by centrifugal ultrafiltration, and then both were mixed in various proportions. Aliquots of these mixtures were then diluted and amplified in triplicates. The PCR products were electrophoresed alongside the corresponding original mixtures, ethidium bromidestained, and analyzed by computer den-

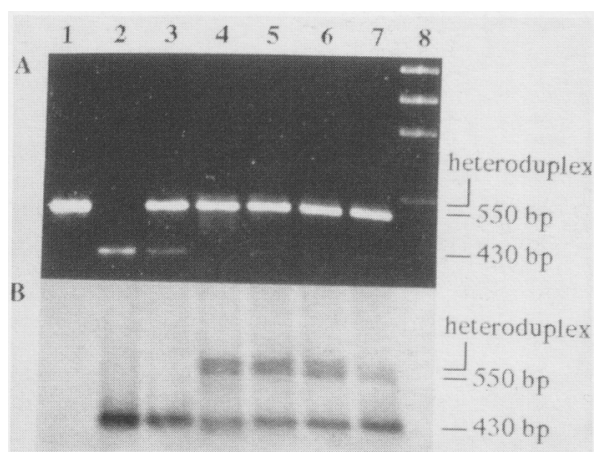

FIGURE 3 Visualization of heteroduplexes. A 550-bp fragment of G. mossae SSU rDNA was amplified using the VANS1/NS21 primers (lane 1). The 430-bp truncated rDNA fragment was separately amplified from $E$. coli XL1-Blue containing the pSTVA1 plasmid using the VANS1/NS21 primers but with $\left[\alpha^{35}\right.$ S $]$ dATP added (lane 2 ). The two amplified products were mixed (lanes 3-7) and 20- $\mu$ l aliquots of this mixture were subjected to a different denaturation-renaturation temperature cycle: (lane 3), no treatment; (lane 4) $95^{\circ} \mathrm{C}, 1 \mathrm{~min}$ and rapid cooling to $4^{\circ} \mathrm{C}$; (lane 5 ), $95^{\circ} \mathrm{C}, 1$ $\mathrm{min}$, cool to $55^{\circ} \mathrm{C}$ in $5 \mathrm{~min}$, then rapid cooling to $4^{\circ} \mathrm{C}$; (lane 6) $95^{\circ} \mathrm{C}, 1 \mathrm{~min}$, cool to $55^{\circ} \mathrm{C}$ in 15 min, then rapid cooling to $4^{\circ} \mathrm{C}$; (lane 7) $95^{\circ} \mathrm{C}$, $1 \mathrm{~min}$, cool to $55^{\circ} \mathrm{C}$ in $60 \mathrm{~min}$, then rapid cooling to $4^{\circ} \mathrm{C}$. Following electrophoresis in $2 \%$ NuSieve-1\% SeaKem agarose, the gel was stained with ethidium bromide, photographed $(A)$, dried, and autoradiographed for 2 days $(B)$. The heteroduplex band is seen to migrate slower than the 550-bp fragment, and appears only when the two homoduplexes are subjected to a denaturation-renaturation cycle. The amount of heteroduplexes is seen to be decreased by a slow renaturation temperature profile (lane 7). (Lane 8) $\phi X 174 /$ Haell DNA size marker.

sitometry. Even with a slow renaturation step at the end of the PCR, heteroduplexes were sometimes detected. Whenever detected, heteroduplexes were measured and the band intensities of the 500-bp and 430-bp fragments were corrected accordingly. The smaller 430-bp was favored systematically when the initial ratio of templates was in the range of $0.1-10$. A correction factor was computed by comparing the initial ratio of the templates to the ratio measured following a 100,000-fold dilution and 30cycle PCR. This correction factor was uniform over the range of ratios useful for quantitation, that is, $0.2-4$ (Fig. 4) . It was also shown not to be affected by the initial concentration of templates, since similar results were obtained with 1000 and 10,000-fold dilutions. A correction 


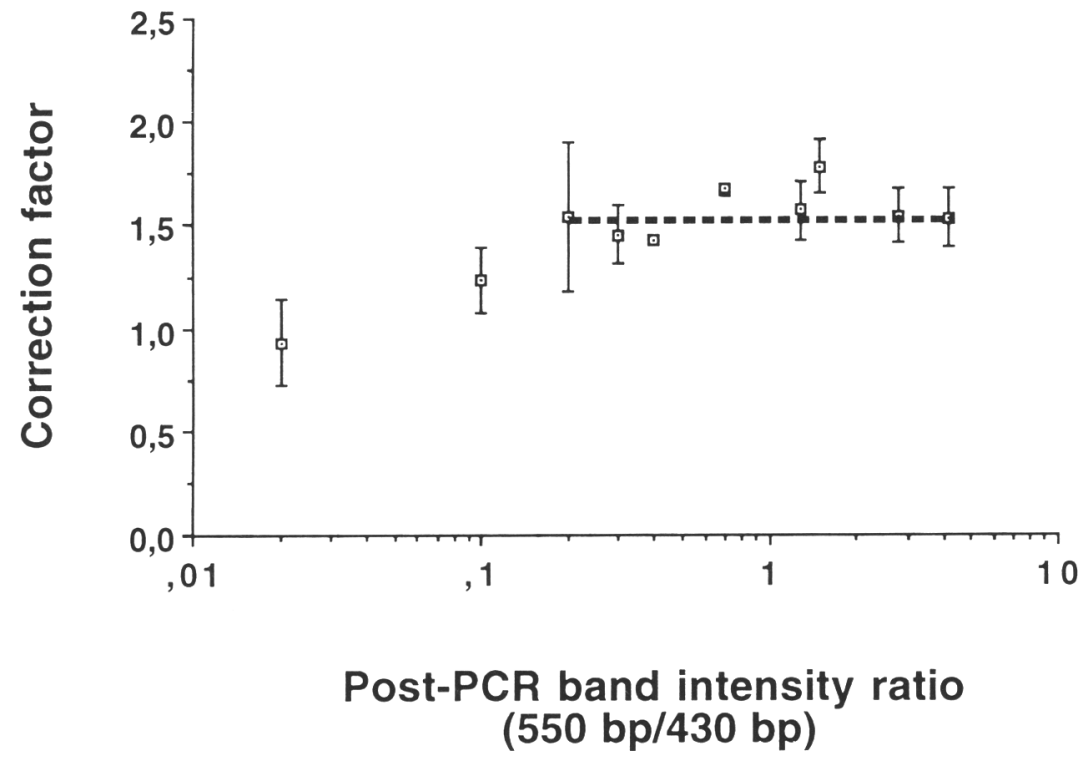

FICURE 4 Correction for yield differences. The 550-bp and 430-bp fragments were separately amplified and purified by centrifugal ultrafiltration, and both were mixed in various proportions. Aliquots of these mixtures were then diluted 100,000-fold and amplified for 30 cycles, followed by a slow renaturation step of $95^{\circ} \mathrm{C}$ to $60^{\circ} \mathrm{C}$ in $2 \mathrm{hr}$. The PCR products were electrophoresed alongside the corresponding original undiluted mixtures, ethidium bromide-stained, and analyzed by computer densitometry. Whenever detected, heteroduplexes were measured and the band intensities of the 550-bp and 430-bp fragments were corrected accordingly. The 550-bp/ 430-bp band intensity ratio was compared before and after PCR. The smaller 430-bp fragment was favored systematically when the initial ratio of templates was in the range of $0.1-10$. The correction factor was computed using the calculation:

Correlation factor $=\frac{\text { original band intensity ratio }(550-\mathrm{bp} / 430-\mathrm{bp})}{\text { post-PCR band intensity ratio }(550-\mathrm{bp} / 430-\mathrm{bp})^{*}}$

* corrected for heterodulexes formation when detected. The means of three replicate PCR assays are plotted, \pm SD.

factor of 1.5 can be used to compensate the bias in post-PCR band intensity ratios (550-bp/430-bp).

The internal standard was constructed via a low-copy-number plasmid, pCL1920, and included in the form of live bacterial cells prior to total DNA extraction. The stringent control of pCL1920 plasmid copy number ${ }^{(5)}$ allows the precise dosage of internal standard DNA molecule: a simple enumeration of bacterial cells containing an average of five copies per cell of the pSTVA1 plasmid. Known amounts of cells can be added to an unknown sample in which the quantity of arbuscular fungi needs to be determined. After DNA extraction and PCR amplification using VANS1/NS21 primers, the ratio of the two amplified products will allow the calculation of initial fungal rDNA SSU gene copy number in the sample. The precision of the result can be estimated by statistical analyses and is a function of the number of replicates used in the calculation. Using this procedure, the quantity of Glomus vesiculiferum in a leek root sample was calculated to be $5 \times 10^{4} \pm 1$ gene copies/mg fresh weight (Table 1 ).

\section{DISCUSSION}

The procedure used to produce the truncated rDNA fragment is rapid and efficient. The suitability of the amplified truncated rDNA fragment for co-amplification with target DNA can even be assessed prior to the cloning step. The stability in plasmid copy number of pCL1920 allows for the accurate determination of the number of copies of the truncated rDNA added as internal standard. By adding the internal standard in the form of live cells prior to DNA extraction, yield variations in both the extraction and amplification steps are taken into account. It should be possible to include in the calculation a factor that would take into account a systematic difference in DNA extraction efficiency for bacteria and fungi, whenever this information becomes available. Despite being influenced by many experimental parameters, the intensity of ethidium bromide staining can be used reliably to quantitate the relative concentration of the two co-amplified fragments, following agarose gel electrophoresis. Densitometric analysis of digitized images of the same gel obtained by ethidium bromide staining and autoradiography gave similar results. Because both techniques are mass dependent, a correction for relative molecular weights of analyte and standard was introduced in the calculation by way of a 0.78 factor $(430 / 550=0.78)$.

The main assumption of quantitative PCR is that the two template DNAs, the target and the truncated internal standard, are amplified at the same rate. This should be true if they were subjected to the same PCR conditions, as is the case when both are co-amplified in the same tube, with the same primers. In addition, there should be an equimolar ratio of the two template DNAs, otherwise, given

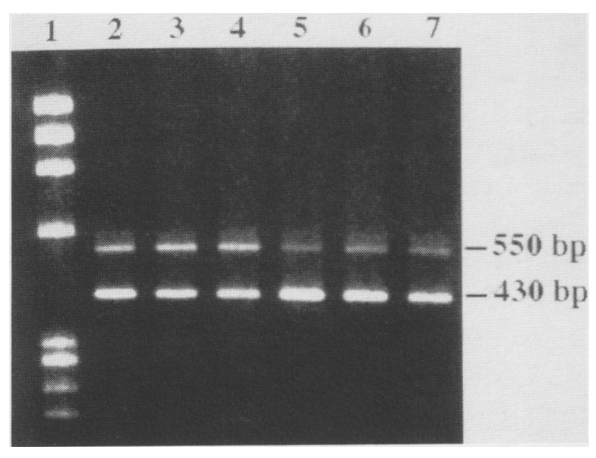

FIGURE 5 Quantitative PCR using VANS1/ NS21 primers. Leek roots colonized with Glomus vesiculiferum were collected, frozen in liquid nitrogen, ground with a mortar and pestle, and stored at $-80^{\circ} \mathrm{C}$. A portion of this sample was weighed and distributed in $10-\mathrm{mg}$ aliquots, to which $1.5 \times 10^{5}$ (lanes 2,3 , and 4) or $3 \times 10^{5}$ (lanes 5, 6, and 7) E. coli XL1-Blue cells containing the pSTVA1 plasmid were added. These aliquots were separated in thirds and treated separately. After total DNA extraction, PCR amplifications were performed using VANS1/NS21 primers, and the last cycle ended with a slow renaturation step. The amplified products were analyzed by agarose electrophoresis, ethidium bromide-stained, and photographed. (Lane 1) $\phi X 174 /$ HaeIII DNA size marker. 
TABLE 1 Determination of VA Endomycorrhizal Fungi rDNA SSU Gene Copy Number in a Colonized Leek Root Sample

\begin{tabular}{lcccc}
\hline $\begin{array}{l}\text { Sample } \\
\text { (lane number } \\
\text { from Fig. 4) }\end{array}$ & $\begin{array}{l}\text { Intensity }{ }^{\mathrm{a}} \text { of } \\
\mathbf{5 5 0 - b p ~ b a n d ~}^{\text {Intensity }}\end{array}$ & $\begin{array}{l}\text { a of } \\
\text { 430-bp band }\end{array}$ & $\begin{array}{l}\text { Ratio } \\
550 / 430\end{array}$ & $\begin{array}{l}\text { Calculated } \\
\text { concentration }^{\mathrm{b}} \\
\text { (gene copies/mg) }\end{array}$ \\
\hline 2 & 1728 & 2822 & .61 & $5.4 \times 10^{4}$ \\
3 & 1714 & 2372 & .72 & $6.3 \times 10^{4}$ \\
4 & 1745 & 2142 & .81 & $7.2 \times 10^{4}$ \\
5 & 448 & 2926 & .15 & $2.7 \times 10^{4}$ \\
6 & 769 & 2494 & .30 & $5.2 \times 10^{4}$ \\
7 & 679 & 2196 & .31 & $5.4 \times 10^{4}$ \\
\hline
\end{tabular}

${ }^{a}$ Measured by densitometry using computer image analysis of the digitized photograph.

bUsing the calculation:

VA fungi SSU rDNA = "ratio 550/430" $\times 1.5 \times 0.78 \times 5 \times$ number of $E$. coli cells/root weight; root weight $=10 \mathrm{mg}$; number of $E$. coli cells $=1.5 \times 10^{5}$ or $3 \times 10^{5}$ (see Fig. 4 ).

the exponential nature of the PCR process, this ratio would be expected to be influenced by variables such as the initial template concentration or number of PCR cycles. It has been observed that when different-sized alleles are simultaneously amplified, for example in PCR of VNTR (variable number of tandem repeats) loci of a heterozygous individual, the yield is often higher for the shorter allele. ${ }^{(8)}$ In the present work, it was observed that both amplified products could be visualized when the initial template ratio was between $10^{2}$ and $10^{-2}$, but that a systematic bias in favor of the smaller 430-bp fragment was found when the initial template ratio was between $10^{1}$ and $10^{-1}$. A correction factor of 1.5 was included in the calculation to compensate for this bias, and should be reliable as long as the same PCR conditions are used. The proposed protocol to quantitate the arbuscular endomycorrhizal rDNA fungal genes accurately is a two-step process: a first approximation is obtained by amplifying the sample with a different concentration of the internal standard; next, a more accurate result is obtained by amplifying with a template ratio close to 1 . The number of replications to be carried out will be dictated by the level of accuracy required.

Heteroduplex formation might interfere with the accurate determination of the ratio of amplified products, but it can be reduced by a slow renaturation step at the end of the PCR. If needed, the electrophoretic separation conditions may be further optimized by decreasing the electric field intensity or using acrylamide gels to resolve the heteroduplex band better and use its quantity in the calculation of the ratio of amplified products.

The results are currently expressed in number of ribosomal genes per sample, which should be a reliable biomass indicator. Further work will be required to determine their genome copy number in endomycorrhizal fungi, and thus translate the results in number of genomes per sample.

For the colonized leek roots sample used in the present work, a precision of $20 \%$ was achieved with six replicates, which is sufficient for many ecological and practical applications. This quantitative technique should prove useful in the determination of total endomycorrhizal fungi in soil and other substrates.

\section{ACKNOWLEDGMENTS}

We thank S. Chabot for the gift of Allium porum plants colonized by Glomus vesiculiferum. This work was supported in part by an operating grant from the Natural Sciences and Engineering Research Council of Canada to M.L. (No. A-2920). Work in R.C. Lévesque's laboratory was funded by the MRC and the Canadian Bacterial Diseases Network.

1. Gilliland, G., S. Perrin, and H.F. Bunn. 1990. Competitive PCR for quantitation of mRNA. In PCR protocols, a guide to methods and applications (ed. M.A. Innis et al.), pp. 60-69. Academic Press, San Diego.

2. Wang, A.M. and D.F. Mark. 1990. Quantitative PCR. In PCR protocols, a guide to methods and applications (ed. M.A. Innis et al.), pp. 70-75. Academic Press, San Diego.

\section{REFERENCES}

3. Henco, K. and M. Heibey. 1990. Quantitative PCR: The determination of template copy numbers by temperature gradient gel electrophoresis (TGGE). Nucleic Acids Res. 18: 6733-6734.

4. Simon, L., M. Lalonde, and T. D. Bruns. 1992. Specific amplification of 18 S fungal ribosomal genes from vesicular-arbuscular Endomycorrhizal fungi colonizing roots. Appl. Environ. Microbiol. 58: 291295.

5. Lerner, C.G. and M. Inouye. 1990. Low copy number plasmids for regulated lowlevel expression of cloned genes in Escherichia coli with blue/white insert screening capability. Nucleic Acids Res. 18: 4631.

6. McCabe, P.C. 1990. Production of singlestranded DNA by asymmetric PCR In PCR protocols, a guide to methods and applications) ed. M.A. Innis et al.), pp. 76-83. Academic Press, San Diego.

7. Zorn, A.M. and P.A. Krieg. 1991. PCR Analysis of alternative splicing pathways: Identification of artifacts generated by heteroduplex formation. Biotechniques 11: $180-184$.

8. Horn, G.T., B. Richards, and K.W. Klinger. 1989. Amplification of a highly polymorphic VNTR segment by the polymerase chain reaction. Nucleic Acids Res. 17: 2140 .

Received for publication October 23, 1991; accepted in revised form March 27, 1992. 


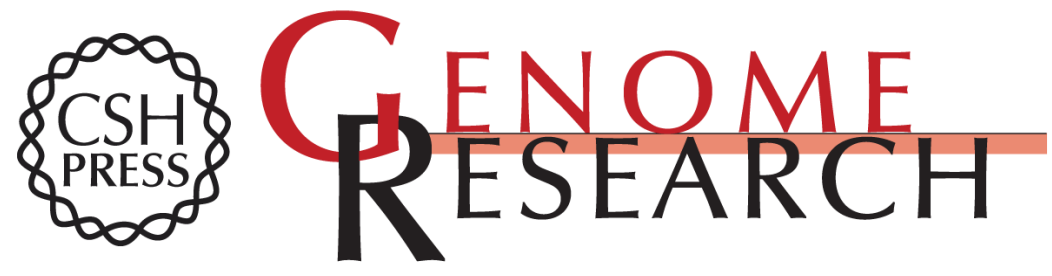

\section{Rapid quantitation by PCR of endomycorrhizal fungi colonizing roots.}

L Simon, R C Lévesque and M Lalonde

Genome Res. 1992 2: 76-80

Access the most recent version at doi:10.1101/gr.2.1.76

References This article cites 5 articles, 1 of which can be accessed free at:

http://genome.cshlp.org/content/2/1/76.full.htmI\#ref-list-1

\section{License}

Email Alerting Receive free email alerts when new articles cite this article - sign up in the box at the Service top right corner of the article or click here.

\section{Affordable, Accurate Sequencing.}

To subscribe to Genome Research go to: https://genome.cshlp.org/subscriptions 